\title{
MAPEAMENTO DE FACHADAS DUPLAS NO BRASIL: TECNOLOGIAS E MATERIAIS APLICADOS
}

\author{
MELA, Débora \\ Universidade Federal de Viçosa UFV, e-mail: debora.melaa@gmail.com \\ TIBÚRCIO, Túlio Márcio de Salles \\ Universidade Federal de Viçosa UFV, e-mail: tmst83@hotmail.com
}

\begin{abstract}
RESUMO
Atualmente, o mercado possibilita uma variedade de elementos e configurações de fachadas, variando em materiais, orientação solar, tamanho de janelas, tipo de vidro e, consequentemente, no orçamento. Dentre as configurações possíveis de fachadas, uma que vem se destacando em projetos de edifícios, tornando-se um importante elemento arquitetônico, que aproveita sistemas solares passivos, é a Fachada Dupla, um sistema muito utilizado em climas mais frios como na Europa e, principalmente, na Alemanha. Esta pesquisa é parte dos resultados de uma dissertação de mestrado e teve como objetivo caracterizar como essas fachadas duplas estão sendo inseridas no clima brasileiro, e os tipos de materiais que estão sendo aplicados nesta segunda pele da fachada. O estudo qualitativo utilizou como metodologia estudos de casos múltiplos e levantamento bibliográfico para identificação dos materiais que estão sendo aplicados como segunda pele para o projeto dessas fachadas no Brasil. Os resultados mostraram que, no Brasil, além da utilização da fachada dupla de vidro, outros seis tipos diferentes de materiais têm sido usados nessa segunda pele em edifícios, sendo elas: chapa metálica, membrana têxtil, madeira, concreto polímero, vergalhão de aço e os cabos de aço inox.
\end{abstract}

Palavras-chave: Fachadas Inteligentes, Fachada Dupla, Segunda Pele, Clima Tropical Brasileiro.

\begin{abstract}
Currently, the construction industry enables a variety of elements and configurations of facades, varying in materials, solar orientation, window size, type of glass and, consequently, in the budget. Among the possible configurations of façades, one that has been prominent in building projects, becoming an important architectural element, which takes advantage of passive solar systems, is the Double Skin Facade. It is a system widely used in colder climates such as in Europe and, mainly, in Germany. This research is part of the results of a master's dissertation and had the objective of characterizing how these double skin façades are being inserted in the Brazilian climate, and the types of materials being applied. This qualitative study used multiple case studies and literature review as methodology to identify the materials that are being applied as second skin for the design of these façades in Brazil. Results showed that, in addition to the use of the double glass facade in Brazil, six different types of materials have been used in this second skin in buildings, such as metal plate, textile membrane, wood, polymer concrete, steel rebar and Stainless steel cables.
\end{abstract}

Keywords: Intelligent Facades, Double Skin Facade, Second Skin, Brazilian Tropical Climate.

\section{INTRODUÇÃO}

Visto que uma parte considerável da vida humana acontece no interior de espaços edificados, a qualidade ambiental e bem-estar nesses ambientes

MELA, D.; TIBÚRCIO, T. M. S. Mapeamento de fachadas duplas no brasil: tecnologias e materiais aplicados. In: SIMPÓSIO BRASILEIRO DE QUALIDADE DO PROJETO NO AMBIENTE CONSTRUÍDO, 6., 2019, Uberlândia. Anais... Uberlândia: PPGAU/FAUeD/UFU, 2019. p 679-691. DOI https://doi.org/10.14393/sbqp19063. 
refletem diretamente na satisfação do modo de morar e no bom rendimento da produtividade de trabalho desses usuários (CROOME, 2004). Dessa forma, a concepção de edifícios, que por vezes priorizam valores estético-formais, o desempenho do ambiente construído e sua qualidade funcional, passou a ser um desafio profissional para arquitetos e projetistas, instigando uma busca cada vez mais ampla por soluções arquitetônicas que contribuam com o meio ambiente e o contentamento do ser humano que habita esses espaços.

Nesse contexto, as fachadas de edifícios inteligentes (TIBÚRCIO, 2007) oferecem um meio privilegiado para atuar e se propor soluções arquitetônicas construtivas, capaz de controlar a passagem de iluminação, calor, som e ventilação para o ambiente interno (BAROZZl et al., 2016).

Dentre as possibilidades de fachadas inteligentes, um sistema que vem ganhando popularidade na prática de construção da fachada de edifícios é a fachada dupla, que usa a transparência como recurso estético. Esse sistema envolve a adição de uma segunda camada (segunda pele) à fachada convencional, criando uma cavidade de ar entre as camadas (ALBERTO; RAMOS; ALMEIDA, 2017; BARBOSA, 2015; MAZZAROTO, 2011; POIRAZIS, 2004). Porém, a aplicação dessa tipologia de fachada em países de clima tropical, como no Brasil, ainda é muito recente, o que denota a necessidade para mais investigações sobre o tema, principalmente, no sentido de se estabelecerem indicadores para se alcançar a qualidade e o bem-estar dos usuários em edifícios que incorporam tal solução tecnológica.

Apesar de a maioria dos estudos dedicados às fachadas duplas terem foco o uso do vidro como material para a segunda camada, outros materiais têm sido recentemente considerados para o projeto da segunda pele como, por exemplo: membrana têxtil (PAECH, 2016); a membrana de PVC (ZHANG et al., 2016); chapa metálica perfurada (BLANCO et al., 2016); tela reticulada de cabos de aço inox (AECWEB, 2017); vergalhão de aço (ARCHDAILY, 2014); painéis de concreto polímero (ULMA, 2017); e a madeira (STAZI et al., 2014).

No entanto, embora diferentes possibilidades de materiais terem sido considerados, ainda há falta de estudos que considerem a influência da condição climática sobre o desempenho ambiental da fachada dupla, além de comparações entre fachadas com diferentes materiais, a fim de fornecer suporte técnico para projetistas ao determinar o tipo de material mais adequado para um determinado projeto em um determinado clima (ZHANG et al., 2016).

Diante disto, este artigo tem como principal objetivo apresentar alguns dos materiais que estão sendo utilizados como segunda pele para o projeto da fachada dupla no Brasil, além do vidro. Para isso, foi empregado o método de estudos de casos múltiplos, onde foi possível comparar a diversidade de materiais que estão sendo empregados na camada externa da fachada dupla, em condições climáticas brasileiras.

\subsection{Fachada dupla}

O termo "Fachada Dupla" passou a ser difundido a partir de 1990, e utilizado intensamente na Europa, principalmente, em edifícios coorporativos. Essa tendência foi impulsionada pela exploração da transparência na arquitetura e inovações tecnológica do vidro. 
Em períodos mais quentes, grandes áreas envidraçadas passaram a se tornar um problema nos edifícios já no século XIX na Europa. Foi quando em 1849, Jean-Baptiste Jobar, sugeriu uma versão de fachada dupla ventilada, mencionando que $o$ ar entre panos de vidro pudesse ser aquecido ou resfriado intencionalmente e assim modificar o comportamento das grandes fachadas envidraçadas (BRAHAM, 2005). Com essa definição, configurava-se uma das primeiras versões de fachada dupla mecanicamente ventilada.

Segundo Barbosa et al., (2013, p.122) "a fachada dupla é composta, em geral, de uma camada de vidro colocada a certa distância da camada interior, e juntas formam uma cavidade, permitindo que o ar circule entre elas". Mazzaroto (2011) explica que:

No inverno, a fachada dupla representa uma cobertura adicional para o edifício, e no verão poderá ser sua proteção do sol [...]. No espaço entre as duas camadas, podem ser alocados dispositivos de proteção solar, para sombreamento, mantendo o espaço para circulação do ar, de forma que a temperatura do ar interno se mantenha o mais próximo possível do ar externo. As aberturas da fachada dupla podem ser abertas no verão para permitir a circulação do ar, e fechadas no inverno para criar uma camada isolante, reduzindo as perdas de calor do edifício (MAZZAROTTO, 2011, p. 19).

A cavidade formada por esses dois panos de vidro funciona como um isolamento contra as temperaturas extremas, os ventos fortes e ruídos (POIRAZIS, 2004; MAZZAROTTO, 2011; BARBOSA; TIBÚRCIO, 2012). Em outras palavras, Poirazis (2004) diz que esse sistema de fachada se caracteriza como um vidro que cobre um ou mais pavimentos de um edifício, composta por várias camadas, onde as peles podem ser estanques ou não à entrada do ar. O fluxo do ar na cavidade intermediária pode ser de três formas: natural, mecânica ou artificial. Essa ventilação que passa na cavidade, a origem e o destino do ar pode ser diferente dependendo, principalmente, das condições climáticas, do uso, da localização, do período de ocupação do edifício e da estratégia utilizada. (MAZZAROTTO, 2011).

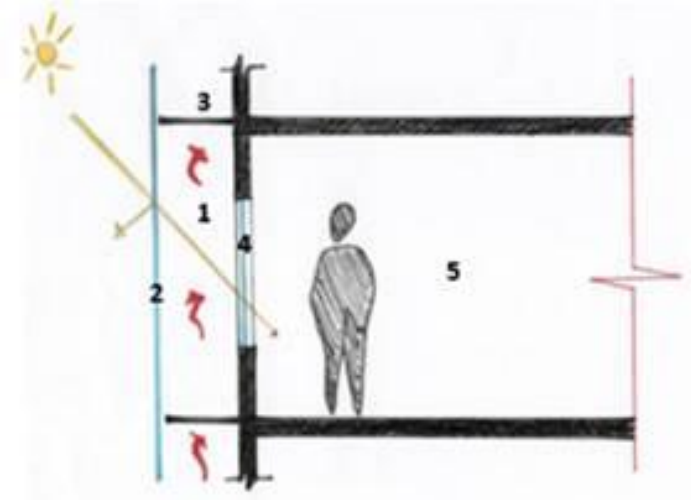

OPÇÃO (A)

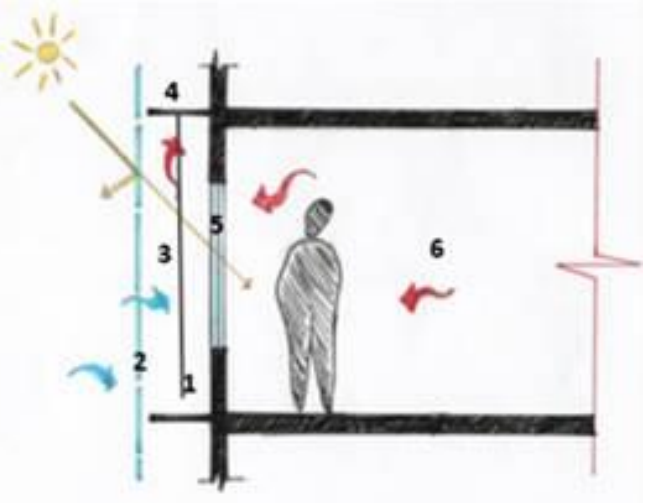

OPÇ̄̃o (B)

Figura 1 - Principais componentes da fachada dupla. Opção A: (1) Cavidade intermediária, (2) Pele externa, geralmente em vidro, (3) Grade para manutenção, (4) Janela operável interna, (5) Ambiente interno do edifício. Opção B: (1) Cavidade intermediária, (2) Pele externa, geralmente em vidro, (3) Dispositivo de sombreamento, (4) Grade para manutenção, (5) Janela operável interna, (6) Ambiente interno do edifício -

Fonte: Autores (2019) 
As vantagens deste tipo de fachada, é permitir que o funcionamento do edifício seja mais dinâmico, procurando se adaptar ao momento climático do ano com menor dependência da climatização artificial. Além disso, esse sistema apresenta bom isolamento acústico, proteção contra incêndio, visão estética, desempenho energético. A Figura 1 mostra um esquema desse sistema.

Como podemos ver na Figura 1, geralmente, essas são as principais características que as fachadas duplas apresentam: uma abertura para exaustão do ar para o exterior, um dispositivo de sombreamento, uma janela operável interna, a pele externa, uma cavidade intermediária, a abertura para insuflamento do ar externo, a pele interna, e uma grade para manutenção.

\section{METODOLOGIA}

Trata-se de uma pesquisa qualitativa, com caráter exploratório-descritivo porque busca entender e caracterizar o objeto de estudo desta pesquisa, as fachadas duplas. O método adotado parte de uma revisão de literatura seguido de estudos de casos múltiplos realizados para identificar os novos materiais que vem sendo aplicados como segunda pele em edifícios brasileiros. As avaliações foram feitas por observação direta, utilizando a pesquisa eletrônica, primeiramente, para encontrar os edifícios e em seguida observar os mesmos para coleta de dados qualitativos.

Nesta pesquisa, edifícios brasileiros que apresentavam uma segunda pele (fachada dupla), transmitindo a ideia mostrada na Figura 2 (A) foram investigados.

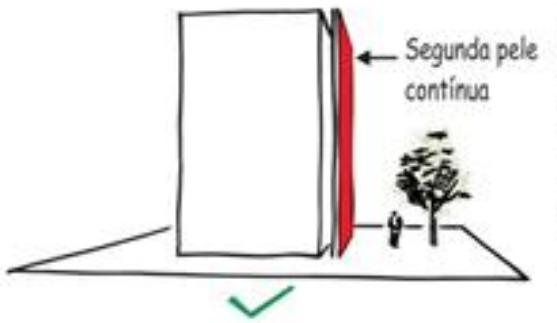

(A)

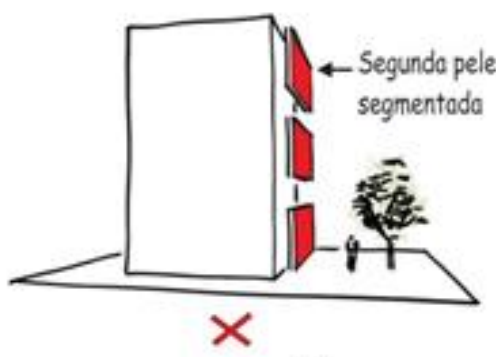

(B)

Figura 2 - Esquema da segunda pele que foi considerada para o estudo (A) Fonte: Autores (2019)

Para a realização dos estudos de casos múltiplos, a pesquisa teve como foco estratégico a identificação dos materiais que estão sendo utilizados como segunda pele para o projeto da fachada dupla no Brasil, além do vidro. Ao todo, foram identificados 26 edifícios que utilizam a tecnologia de fachadas duplas. No entanto, como o foco dessa pesquisa foi mostrar outros materiais que estão sendo utilizados como segunda pele para essas fachadas, os edifícios encontrados com fachada dupla de vidro não serão apresentados neste artigo. 
Contou-se com o apoio da pesquisa eletrônica, onde foram citadas palavraschaves mais aderentes ao tema pesquisado. Estas foram utilizadas como entrada no banco de dados de projetos dos sites ArchDaily Brasil e Arcoweb. As principais expressões utilizadas para essa busca foram: "Fachadas Duplas"; "Fachadas com dupla pele"; "Fachadas para o clima tropical"; "Envelopes de edifícios"; "Segunda pele de edifícios".

Além dessa busca na plataforma online da ArchDaily e Arcoweb, a busca em Bases de Dados Bibliográficos também foi aderida para a pesquisa. Nela foram utilizadas as mesmas expressões nas plataformas online da Elsevier e Science Direct Books: "Double skin" (GRATIA; DE HERDE, 2007)," Double skin facades" (ALBERTO; RAMOS; ALMEIDA, 2017), "Building envelope" (GHAFFARIANHOSEINI et al., 2016), "Facades with second skin", "Double façades for the tropical climate" (BARBOSA; IP; SOUTHALL, 2015)

\section{RESULTADOS}

Dos 26 edifícios com fachada dupla encontrados com os estudos de casos múltiplos, 20 apresentam outros seis tipos diferentes de materiais aplicados nessa segunda pele da fachada, sendo: chapa metálica, tela de cabo de aço inox, membrana têxtil, madeira, vergalhão de aço e concreto polímero, conforme é mostrado na sequência de cada quadro.

Para melhor entendimento, os edifícios estudados são nomeados como "Caso 1 ao Caso 20" nos quadros a seguir, para facilitar a referência no momento de redigir as próximas análises dos resultados. As informações desses quadros estão divididas por localização e autores, parâmetros técnicos, os materiais aplicados na segunda pele e a região que cada edifício se encontra.

\subsection{Chapas metálicas}

Foram encontrados dez exemplos de edifícios que empregaram esse material como fachada dupla (Quadro 1). Os casos encontrados estão localizados no Sul, Sudeste e Centro-Oeste do país, com maior concentração na região Sudeste. Além disso, observa-se que a maior parte dos edifícios que foram encontrados usando a chapa metálica como fachada dupla no Brasil é de uso corporativo e estão distribuídos até 11 pavimentos.

As composições da superfície dessas fachadas são formadas por painéis de chapas metálicas perfurada na cor branca, fixados em uma estrutura metálica e encostados um ao lado do outro, onde juntos formam uma única pele e não podem ser abertas. Os únicos casos encontrados no Brasil que permitem a abertura dessas fachadas são os Casos 02,08 e 10 porque possuem uma superfície formada por painéis verticais que podem ser rotacionados de acordo com o ângulo desejado. Todos os casos encontrados apresentam um grau de perfuração nas chapas, o que permite a iluminação natural e ventilação entre as fachadas, porém, o Caso 06 apresenta placas 100\% impermeáveis ao vento e a passagem da radiação solar. Para a entrada de luz e ar no Caso 06, as placas são movimentadas ao ângulo desejado.

Alguns autores, como Blanco et al. (2014) e Minioli (2014), afirmam que quanto maior essa taxa de perfuração, menor a diferença de temperatura com o exterior, e a utilização de alumínio na cor branca como foi visto, é mais favorável. Quanto aos aspectos ambientais, esse material se enquadra em 
tecnologias passivas, pois não dependem de acionamento mecânico para atuarem. Além disso, o uso destes componentes proporciona ao usuário uma integração visual com o ambiente externo.

No entanto, vale ressaltar que o uso errado desse material pode infelizmente levar a condições gerais de desconforto no interior do edifício, além do aumento do consumo de energia. Alguns autores orientam que aplicação desses materiais em clima quente-úmido, devemos manter a chapa metálica afastada da janela interna do edifício, criando um espaço de ar ventilado para propiciar um sombreamento e auxiliar na dissipação do ar quente. Já em condições de climas frios, o autor diz que as chapas perfuradas podem ser aplicadas próximas à fachada da edificação, sem apresentar uma cavidade ventilada. Pois assim, irá ocorrer um acúmulo de calor que irá ajudar aquecer a edificação (MINIOLI, 2014).

\section{Quadro 01 - Edifícios encontrados com Chapa Metálica}

\begin{tabular}{|c|c|c|c|c|c|c|}
\hline \multicolumn{7}{|c|}{ FACHADA DUPLA DE CHAPA METÁLICA } \\
\hline Casos & Imagem & $\begin{array}{c}\text { Autor/ } \\
\text { Escritório }\end{array}$ & $\begin{array}{l}\text { Número } \\
\text { de pav. }\end{array}$ & $\begin{array}{c}\text { Finalidade/ } \\
\text { Uso }\end{array}$ & $\begin{array}{c}\text { Características } \\
\text { do Material }\end{array}$ & Região \\
\hline 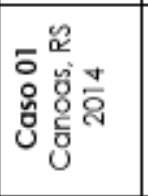 & & $\begin{array}{c}\text { Escritório: } \\
\text { OSPA }\end{array}$ & $\begin{array}{c}\text { Térreo + } \\
5 \text { pav. }\end{array}$ & Universidade & $\begin{array}{c}\text { Chapa } \\
\text { perfurada de } \\
\text { alumínio Branco } \\
\text { com } 30 \% \text { de } \\
\text { perfuração }\end{array}$ & Sul \\
\hline 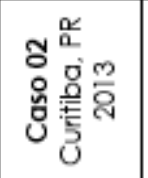 & & $\begin{array}{c}\text { Escritório: } \\
\text { Luiz } \\
\text { Volpato } \\
\text { Arquitetura }\end{array}$ & $\begin{array}{c}\text { Térreo + } \\
3 \text { pav. }\end{array}$ & Corporativo & $\begin{array}{l}\text { Chapas de aço } \\
\text { galvanizadas e } \\
\text { perfurada na } \\
\text { cor cinza }\end{array}$ & Sul \\
\hline 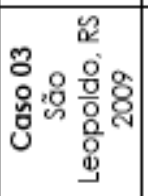 & & $\begin{array}{l}\text { Escritório: } \\
\text { SIAA }\end{array}$ & $\begin{array}{l}\text { Subs. }+ \\
\text { Térreo + } \\
2 \text { pav. }\end{array}$ & Corporativo & $\begin{array}{c}\text { Chapa metálica } \\
\text { perfurada na } \\
\text { cor branca }\end{array}$ & Sul \\
\hline 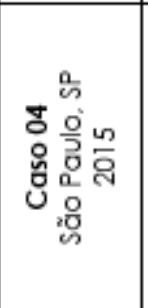 & & $\begin{array}{l}\text { Escritório: } \\
\text { Eduardo } \\
\text { de } \\
\text { Almeida, } \\
\text { Mindlin } \\
\text { Loeb + } \\
\text { Dotto } \\
\text { Arquitetos }\end{array}$ & $\begin{array}{c}\text { Térreo + } \\
2 \text { pav. }\end{array}$ & Universidade & $\begin{array}{c}\text { Chapa metálica } \\
\text { perfurada na } \\
\text { cor Cinza }\end{array}$ & Sudeste \\
\hline 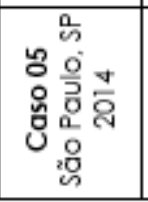 & & $\begin{array}{l}\text { Escritório: } \\
\text { Techne } \\
\text { Arquitetos } \\
\text { Associados }\end{array}$ & 11 pav. & Comercial & $\begin{array}{l}\text { Chapa metálica } \\
\text { perfurada } \\
\text { pré-pintadas em } \\
\text { azul, verde e } \\
\text { cinza }\end{array}$ & Sudeste \\
\hline
\end{tabular}

Continuação do Quadro 01

Continua... 


\begin{tabular}{|c|c|c|c|c|c|c|}
\hline 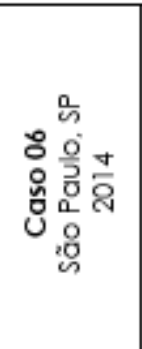 & fi. & $\begin{array}{c}\text { Escritórios: } \\
\text { Base } \\
\text { Urbana, } \\
\text { Kipnis } \\
\text { Arquitetos } \\
\text { associados } \\
e \\
\text { Pessoa } \\
\text { arquitetos }\end{array}$ & $\begin{array}{c}\text { Térreo + } \\
3 \text { pav. }\end{array}$ & Escola & $\begin{array}{l}\text { Chapa metálica } \\
\text { em tons de } \\
\text { laranja e cinza } \\
\text { com } 100 \% \text { de } \\
\text { permeabilidade } \\
\text { e variação de } \\
\text { ângulos }\end{array}$ & Sudeste \\
\hline 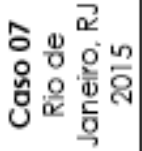 & & $\begin{array}{l}\text { Escritório: } \\
\text { Bernardes } \\
\text { Arquitetura }\end{array}$ & $\begin{array}{l}\text { Térreo + } \\
3 \text { pav. }+ \\
\text { terraço }\end{array}$ & Corporativo & $\begin{array}{c}\text { Chapa metálica } \\
\text { perfurada na } \\
\text { cor branca }\end{array}$ & Sudeste \\
\hline 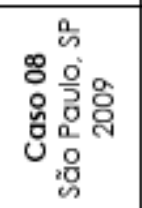 & & $\begin{array}{l}\text { Escritório: } \\
\text { Daniel } \\
\text { Corsi, Dani } \\
\text { Hirano e } \\
\text { Reinaldo }\end{array}$ & $\begin{array}{c}\text { Térreo + } \\
1 \text { pav. }\end{array}$ & Institucional & $\begin{array}{c}\text { Chapa de } \\
\text { alumínio na cor } \\
\text { branca }\end{array}$ & Sudeste \\
\hline 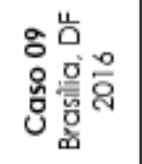 & & $\begin{array}{l}\text { Escritório: } \\
\text { Mira } \\
\text { Arquitetos }\end{array}$ & $\begin{array}{l}\text { Térreo + } \\
2 \text { pav.t } \\
\text { terraço }\end{array}$ & Corporativo & $\begin{array}{c}\text { Chapa de } \\
\text { aluzinco na cor } \\
\text { branca }\end{array}$ & $\begin{array}{c}\text { Centro- } \\
\text { Oeste }\end{array}$ \\
\hline $\begin{array}{l}\text { 음 } \\
\text { 음 을을 } \\
\text { 몬 }\end{array}$ & 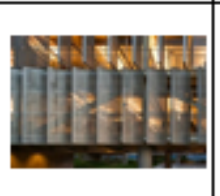 & $\begin{array}{l}\text { Escritório: } \\
\text { gruposp + } \\
\text { Luciano } \\
\text { Margotto }\end{array}$ & $\begin{array}{l}\text { Térreo } \\
\text { inferior, } \\
\text { térreo } \\
\text { superior } \\
+2 \text { pov. }\end{array}$ & Corporativo & $\begin{array}{l}\text { Chapa de aço } \\
\text { carbono de 1,2 } \\
\text { mm, perfurada } \\
\text { e dobrada na } \\
\text { cor cinza }\end{array}$ & $\begin{array}{c}\text { Centro- } \\
\text { Oeste }\end{array}$ \\
\hline
\end{tabular}

Fonte: Elaborado pelos autores (2019)

\subsection{Tela com cabo de aço inox}

O Cabo de Aço Inox, material muito utilizado nas estruturas da construção civil, também têm ganhando espaço nas fachadas, como pode ser visto no Quadro 02. Três edifícios brasileiros nas regiões Sudeste e Centro-Oeste foram encontrados utilizando esse material na segunda pele da fachada dupla.

De acordo com os dados que foram apresentados no Quadro 02, a maior parte dos edifícios que foram encontrados com fachada dupla de cabo de aço inox no Brasil, são de uso corporativo e compõem de 3 a 5 pavimentos. Quanto a superfície que compõe a fachada dupla, essa é composta por uma cortina formada por cabos de aço inox estendidos sobre toda área da fachada do edifício, e possuem a cor natural do aço (cinza). Essa cortina apresenta espaçamentos entre os cabos tornando possível a passagem de ar e outros agentes naturais. 
Quadro 02 - Edifícios encontrados com Tela de cabo em aço inox

\begin{tabular}{|c|c|c|c|c|c|c|}
\hline \multicolumn{7}{|c|}{ FACHADA DUPLA COM TELA DE CABO DE ACO INOX } \\
\hline Casos & Imagem & Autor & $\begin{array}{l}\text { Número } \\
\text { de pav. }\end{array}$ & $\begin{array}{c}\text { Finalidade/ } \\
\text { Uso }\end{array}$ & $\begin{array}{c}\text { Características do } \\
\text { Material }\end{array}$ & Região \\
\hline 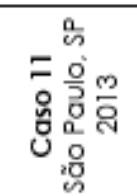 & & $\begin{array}{c}\text { Arquitetos: } \\
\text { Pedro } \\
\text { Taddei e } \\
\text { Francisco } \\
\text { Spadoni }\end{array}$ & $\begin{array}{l}\text { Térreo + } \\
5 \text { pav }\end{array}$ & $\begin{array}{c}\text { Centros } \\
\text { educativos }\end{array}$ & $\begin{array}{c}\text { Cabo de aço inox } \\
\text { na cor cinza }\end{array}$ & Sudeste \\
\hline 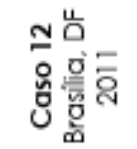 & & $\begin{array}{l}\text { Escritório: } \\
\text { Siegbert } \\
\text { Zanettini }\end{array}$ & $\begin{array}{c}\text { Térreo + } \\
4 \text { pav. + } \\
\text { Solário }\end{array}$ & Corporativo & $\begin{array}{c}\text { Cabo de aço inox } \\
\text { na cor cinza }\end{array}$ & $\begin{array}{l}\text { Centro- } \\
\text { Oeste }\end{array}$ \\
\hline 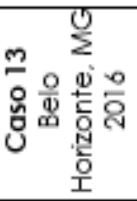 & 23 & $\begin{array}{l}\text { Escritório: } \\
\text { Studio } \\
\text { Prudencio }\end{array}$ & $\begin{array}{l}\text { Térreo + } \\
3 \text { pav. }\end{array}$ & Corporativo & $\begin{array}{c}\text { Cabo de aço inox } \\
\text { na cor cinza }\end{array}$ & $\begin{array}{l}\text { Centro- } \\
\text { Oeste }\end{array}$ \\
\hline
\end{tabular}

Fonte: Elaborado pelos autores (2019)

A vantagem em utilizar a tela metálica para arquitetura é permitir efeitos visuais únicos às fachadas de edifícios projetados em consonância com requisitos de conforto térmico e lumínico, pois a envoltória do edifício é protegida pela tela de aço inox que filtra a incidência de raios solares e permite a ventilação direta, ao mesmo tempo em que propícia um efeito óptico de luz e sombra na malha da tela metálica para fachada.

Além disso, devido à robustez do material e consistência, ele é resistente a intempéries e à corrosão, podendo ser facilmente limpo com apenas a chuva recebida nas zonas exteriores. Outro ponto positivo é que essas telas metálicas se adaptam tanto a grandes dimensões como também a dimensões de difíceis detalhes.

\subsection{Membrana de PVC}

A membrana e tecidos plásticos possuem como vantagens controlar a transmitância de luz, leveza, alta resistência, resistência à corrosão e isolamento térmico. O Quadro 03 mostra três edifícios brasileiros que foram encontrados utilizando esse material como fachada dupla, um na região Centro-Oeste e dois no Sul do país.

Os edifícios encontrados possuem um uso diversificado, variando entre institucional, corporativo e comercial. Já a distribuição desses edifícios varia de 3 a 6 pavimentos. Quanto à cor utilizada, não houve uma frequência entre os casos, cada um adotou um jogo de cores diferente. Porém, os casos que adotaram cores claras terão menos absorção térmica e possivelmente dissiparão mais calor para fora da fachada. Em relação à permeabilidade visual do material, as malhas que são perfuradas são revestidas com PVC e podem atingir até $90 \%$ de transparência para quem está no lado interno do edifício. 
Quadro 03 - Edifícios encontrados com Membrana de PVC

\begin{tabular}{|c|c|c|c|c|c|c|}
\hline \multicolumn{7}{|c|}{ MEMBRANA DE PVC } \\
\hline Casos & Imagem & Autor & $\begin{array}{l}\text { Número } \\
\text { de pav. }\end{array}$ & $\begin{array}{c}\text { Finalidade/ } \\
\text { Uso }\end{array}$ & $\begin{array}{c}\text { Características } \\
\text { do Material }\end{array}$ & Região \\
\hline 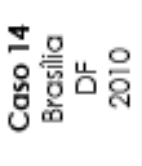 & & $\begin{array}{l}\text { Escritório: } \\
\text { PPMS } \\
\text { Arquitetos } \\
\text { Associados }\end{array}$ & $\begin{array}{l}\text { Térreo + } \\
4 \text { pav. }\end{array}$ & Corporativo & $\begin{array}{l}\text { Membrana de } \\
\text { PVC perfurada } \\
\text { na cor verde }\end{array}$ & $\begin{array}{l}\text { Centro- } \\
\text { Oeste }\end{array}$ \\
\hline 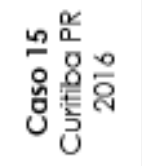 & & $\begin{array}{c}\text { Escritório: } \\
\text { Arqbox } \\
\text { Arquitetura }\end{array}$ & 6 pav. & $\begin{array}{c}\text { Institucional } \\
\text { e } \\
\text { Corporativo }\end{array}$ & $\begin{array}{c}\text { Membrana de } \\
\text { PVC perfurada } \\
\text { na cor branco } \\
\text { gelo }\end{array}$ & Sul \\
\hline 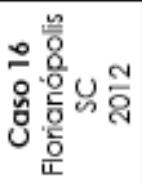 & 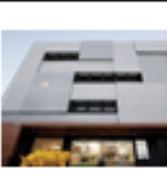 & $\begin{array}{l}\text { Escritório: } \\
\text { Idein }\end{array}$ & $\begin{array}{l}\text { Térreo }+ \\
3 \text { pav. }\end{array}$ & Comercial & $\begin{array}{l}\text { Membrana de } \\
\text { PVC na cor cinza }\end{array}$ & Sul \\
\hline
\end{tabular}

Fonte: Elaborado pelos autores (2019)

Segundo Zhang et al. (2016), essas fachadas de membrana têxtil oferecem oportunidades para a expressão arquitetônica, com formas livres e complexas estruturalmente viáveis e economicamente atraentes. Além disso, possuem como vantagem controlar a transmitância de luz, leveza, alta resistência, resistência à corrosão e isolamento térmico.

\subsection{Madeira}

A crescente popularidade no uso de madeira na indústria da construção tem ganhado espaço em fachadas de edifícios. No Brasil, dois casos que se assemelham à fachada dupla foram encontrados, um no Sudeste e outro no Centro-Oeste do país. O Quadro 04 apresenta esses casos.

Quadro 04 - Edifícios encontrados com Madeira

\begin{tabular}{|c|c|c|c|c|c|c|}
\hline \multicolumn{7}{|c|}{ MADEIRA } \\
\hline Casos & Imagem & Autor & $\begin{array}{l}\text { Número } \\
\text { de pav. }\end{array}$ & $\begin{array}{c}\text { Finalidade/ } \\
\text { Uso }\end{array}$ & $\begin{array}{c}\text { Características do } \\
\text { Material }\end{array}$ & Região \\
\hline 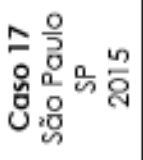 & & $\begin{array}{c}\text { Arq: } \\
\text { Rosenbaum } \\
\text { e Muti } \\
\text { Randolph }\end{array}$ & $\begin{array}{l}\text { Térreo + } \\
1 \text { pav. }\end{array}$ & Comercial & $\begin{array}{l}\text { Madeira plástica } \\
\text { no tom natural }\end{array}$ & Sudeste \\
\hline 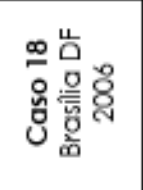 & & $\begin{array}{c}\text { Arq: } \\
\text { Francisco } \\
\text { Fanucci e } \\
\text { Marcelo } \\
\text { Ferroz }\end{array}$ & $\begin{array}{l}\text { Térreo + } \\
4 \text { pav. }\end{array}$ & Comercial & $\begin{array}{c}\text { Madeira no tom } \\
\text { natural }\end{array}$ & $\begin{array}{c}\text { Centro- } \\
\text { Oeste }\end{array}$ \\
\hline
\end{tabular}

Fonte: Elaborado pelos autores (2019)

Com base nas informações acima, a finalidade de uso desses edifícios é o comercial, apresentando uma altura de até 4 pavimentos. Nota-se que os dois casos apresentam características distintas mesmo usando o mesmo material. O Caso 17 adotou a composição dos brises na vertical, que podem mudar de 
ângulo criando pequenas aberturas. Já o Caso 18, usou uma tela em perfilado de madeira na horizontal do edifício.

O uso desse material em fachadas pode trazer muitos benefícios significativos como: economia de energia, conforto e luz natural, especialmente para condições de conforto interior. Segundo Stazi et al. (2014), a madeira apresenta maior capacidade calorífica específica, e menos condutividade térmica. Essa menor condutividade térmica determina as suas propriedades isolantes mais elevadas e, consequentemente, a sua capacidade de armazenar o calor e liberá-lo em um tempo de atraso (durante a noite).

Dependendo tanto da espécie como da sua localização na construção, a madeira pode ser facilmente tratada com conservantes para protegê-la contra agentes externos, quando expostos a ambientes agressivos, estendendo assim um ciclo de vida natural (PELAZ et al., 2017).

\subsection{Vergalhão de Aço}

Esse sistema é um elemento amplamente utilizado na construção civil, e aos poucos tem ganhado espaço na composição e projeto de fachadas. No Brasil, um edifício foi identificado com esse material e está localizado na região Sul como mostra o Quadro 05 a seguir.

Quadro 05 - Edifícios encontrados com Vergalhão de Aço

\begin{tabular}{|c|c|c|c|c|c|c|}
\hline \multicolumn{7}{|c|}{ VERGALHÄO DE AÇO } \\
\hline Casos & Imagem & Autor & $\begin{array}{l}\text { Número } \\
\text { de pav. }\end{array}$ & $\begin{array}{c}\text { Finalidade/ } \\
\text { Uso }\end{array}$ & $\begin{array}{c}\text { Características do } \\
\text { Material }\end{array}$ & Região \\
\hline 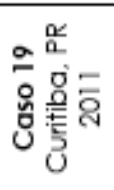 & $\frac{14}{4}$ & $\begin{array}{c}\text { Escritório: } \\
\text { Luiz } \\
\text { Volpato } \\
\text { Arquitetura }\end{array}$ & $\begin{array}{c}\text { Sub. } \\
\text { Solot } \\
\text { térreo+ } \\
3 \text { pav. }\end{array}$ & Corporativo & $\begin{array}{l}\text { Painéis e Malha } \\
\text { com vergalhões } \\
\text { em camadas em } \\
\text { um tom } \\
\text { avermelhado }\end{array}$ & Sul \\
\hline
\end{tabular}

Fonte: Elaborado pelos autores (2019)

Esse edifício apresenta dois tipos de vedação. Nas fachadas Noroeste e Sudeste é formada por chapas de aço patinável, e a fachada Nordeste é compostas por uma malha com vergalhões em camadas, que apoiam 0 paisagismo natural que ainda está em desenvolvimento.

Esse material possui alta resistência e durabilidade, garantindo aplicações que vão da estrutura ao envelopamento de edificações. O uso em fachadas valese dessas propriedades combinadas a outras qualidades técnicas e estéticas. Além disso, seu uso é particularmente recomendado em ambientes altamente agressivos com contato à radiação UV (radiação ultravioleta), além de regiões litorâneas ou industriais.

\subsection{Concreto Polímero}

Atualmente é possível encontrar esse produto em fachadas de edifícios em formato de painéis. No Brasil, um edifício (Quadro 06) foi identificado na região Sudeste, utilizando esse material como fachada dupla. 
Quadro 06 - Edifícios encontrados com Membrana de PVC

\begin{tabular}{|c|c|c|c|c|c|c|}
\hline \multicolumn{7}{|c|}{ CONCRETO POLIMERO } \\
\hline Casos & Imagem & Autor & $\begin{array}{l}\text { Número } \\
\text { de pav. }\end{array}$ & $\begin{array}{c}\text { Finalidade/ } \\
\text { Uso }\end{array}$ & $\begin{array}{c}\text { Características do } \\
\text { Material }\end{array}$ & Região \\
\hline 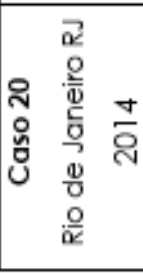 & & $\begin{array}{c}\text { Escritório: } \\
\text { Diller } \\
\text { Scofidio }+ \\
\text { Renfro }\end{array}$ & $\begin{array}{c}2 \text { Sub. + } \\
\text { Térreo + } \\
7 \text { pav. }\end{array}$ & Institucional & $\begin{array}{c}\text { Concreto } \\
\text { Polímero, com } \\
\text { contrastes entre o } \\
\text { preto e o branco } \\
\text { feito com placas } \\
\text { modulares } \\
0,15 \times 0,15 \mathrm{~m} \\
\end{array}$ & Sudeste \\
\hline
\end{tabular}

Fonte: Elaborado pelos autores (2019)

A fachada Oeste desse edifício consiste de um sistema de fachada dupla em concreto polímero, constituída por um mural tridimensional composto de placas modulares de $15 \mathrm{~m}$ por $15 \mathrm{~m}$, em seis tons entre preto e branco. Esse material é constituído por uma combinação de agregados de sílice e quartzo misturados com resinas de poliéster estável. Essa miscelânea é controlada por rigorosos padrões de qualidade, o que assegura o desenvolvimento de um produto de características mecânicas quatro vezes maiores do que às do concreto convencional.

\section{CONCLUSÕES}

A pesquisa identificou que, apesar das fachadas duplas serem bastante difundidas em países com temperaturas amenas, em climas tropicais como o do Brasil, esse sistema também tem sido utilizado nos últimos anos. Além da utilização da fachada dupla convencional de vidro, outros seis tipos diferentes de materiais foram mapeados no Brasil, conforme os 20 edifícios encontrados com a aplicação de materiais como a chapa metálica, membrana têxtil, madeira, concreto polímero, vergalhão de aço e os cabos de aço inox.

Esses edifícios estão em diferentes regiões e cidades brasileiras, sendo que as regiões que mais concentram a utilização de fachadas duplas é a Sudeste, assim como maior diversidade de materiais empregados nesse sistema.

A maioria dos edifícios estudados com fachada dupla no Brasil é de uso corporativo e estão distribuídos até 11 pavimentos. Porém, os casos mais frequentes são de 2 a 3 pavimentos. Geralmente, são edifícios com uma volumetria mais horizontal, traços limpos e tendo abordagem da sustentabilidade como uma das premissas.

A chapa metálica é o material mais utilizado entre os casos estudados onde, geralmente, aparecem na cor branca e com painéis perfurados. Esses painéis são fixados em uma estrutura metálica e encostados um ao lado do outro, onde juntos formam uma única pele sem possibilidade de aberturas. Além de ser um dos mais utilizados no Brasil, esse material possui melhor resistência e menor manutenção do que o vidro.

Existe uma predominância de cores claras em quase todos os fechamentos exteriores, o que colabora para o desempenho térmico ao refletir o máximo de incidência de radiação e, consequentemente, diminuir a transmissão de calor para o interior do edifício. Porém, alguns dos casos apresentados adotaram a cor natural do material, tons mais escuros. 


\section{AGRADECIMENTOS}

À Fundação de Amparo à Pesquisa do Estado de Minas Gerais, ao Programa de Pós-Graduação em Arquitetura e Urbanismo da UFV e ao Grupo de Pesquisa INOVA - CNPq.

\section{REFERÊNCIAS}

ALBERTO, A.; RAMOS, N. M. M.; ALMEIDA, R. M. S. F. Parametric study of doubleskin facades performance in mild climate countries. Journal of Building Engineering, v. 12, n. May, p. 87-98, 2017.

ARCHDAILY. OXI: Luiz Volpato ARQ. Projetos. Edifícios de Escritórios. 2014. Disponível em: <http://www.archdaily.com.br/br/757642/oxi-io-arquitetura> Acesso em: 05 jul. 2017.

BARBOSA, S. A.; TIBÚRCIO, T. M. S.; CARLO, J. C.; GUIMARÃES, I. B. B. E. Método de utilização do programa Energyplus para verificação de desempenho térmico de ambientes com fachadas duplas. Ambiente Construído, Porto Alegre, v. 13, n. 4, p. 121-134, jul./set. 2013.

BARBOSA, S. A.; TIBÚRCIO, T. M. S. Fachadas Duplas Em Clima Tropical De Altitude: Análise Do Potencial De Ventilação De Ambientes Por Meio De Simulação Computacional. XIV ENTAC - Encontro Nacional de Tecnologia do Ambiente Construído, n. 1, p. 4050-4059, 2012.

BARBOSA, S. A. Thermal performance of naturally ventilated office buildings with double skin façade under Brazilian climate conditions. [s.l.] University of Brighton, 2015.

BARBOSA, S. A.; IP, K.; SOUTHALL, R. Thermal comfort in naturally ventilated buildings with double skin façade under tropical climate conditions: The influence of key design parameters. Energy and Buildings, v. 109, p. 397-406, 2015.

BAROZZI, M.; LIENHARD, J.; ZANELLI, A.; MONTICELLI, C. The Sustainability of Adaptive Envelopes: Developments of Kinetic Architecture. Procedia Engineering, v. 155, p. 275-284, 2016.

BLANCO, J. M.; ARRIAGA P.; ROJI, E.; CUADRADO, J. Investigating the thermal behavior of double-skin perforated sheet façades: Part A: Model characterization and validation procedure. Building and Environment, v. 82, p. 50-62, 2014.

BLANCO, J. M. BURUAGA, A.; ROJí, E.; CUADRADO, J.; PELAZ, B. Energy assessment and optimization of perforated metal sheet double skin façades through Design Builder; A case study in Spain. Energy and Buildings, v. 111 , p. 326-336, 2016.

BRAHAM, W. Active Glass Walls: A Typological and Historical Account Active Glass Walls: A Typological and Historical Account. 2005.

CROOME, D. C. Building Environment, architecture and people. In: (Org.). Intelligent Buildings: Design, Management and operation. Cornwall: MGP Books, Lta, 2004. cap,3.

GHAFFARIANHOSEINI, A.; GHAFFARIANHOSEINI, A.; BERARDI, U.; TOOKEY, J.; LI, D. H. W.; KARIMINIA, S. Exploring the advantages and challenges of double-skin 
facades (DSFs). Renewable and Sustainable Energy Reviews, v. 60, p. 10521065, 2016.

GRATIA, E.; DE HERDE, A. Greenhouse effect in double-skin facade. Energy and Buildings, v. 39, n. 2, p. 199-211, 2007.

MAZZAROTO, A. C. E. K. Uso do sistema de fachadas duplas ventiladas em edifícios em Curitiba. Dissertação de Mestrado - PPGCC - Programa de Pós Graduação em Construção Civil - Setor de Tecnologia, Universidade Federal do Paraná, 2011.

MINIOLI, A. R. B. Chapas metálicas perfuradas para protação solar.

Universidade de São Palo - São Paulo, p. 140, 2014.

PAECH, C. Structural Membranes Used in Modern Building Facades. Procedia Engineering, V. 155, P. 61-70, 2016.

PELAZ, B.; BLANCO, J. M.; CUADRADO, J.; EGILUZ, Z.; BURUAGA, A. Analysis of the influence of wood cladding on the thermal behavior of building façades; characterization through simulation by using different tools and comparative testing validation. Energy and Buildings, v. 141, p. 349-360, 2017.

POIRAZIS, H. Double Skin Façades for Office Buildings: Literature Review Report. 2004. Disponível em:

<http://archiglass.nethouse.ru/static/doc/0000/0000/021 1/21 1331.qk1 es 137bl.p df>. Acesso em: 25 mar. 2016.

STAZI, F.; MARINELLI, S.; DI PERNA, C.; MUNAFO, P. Comparison on solar shadings: Monitoring of the thermo-physical behaviour, assessment of the energy saving, thermal comfort, natural lighting and environmental impact. Solar Energy, $v$. 105, p. 512-528, 2014.

TIBÚRCIO, T. M. S. The impact of high-tech learning environments on pupils' interactions. PhD.Thesis. The University of Reading, Reading. UK.2007

ULMA. Architectural Solutions. Fachadas ventiladas. Disponível em:

<http://www.ulmaarchitectural.com/br/fachadas-ventiladas/info-geral/o-quee-uma-fachada-ventilada/> Acesso em: 05 jul. 2017.

ZHANG, T.; TAN, Y.; YANG, H.; ZHANG, X. The application of air layers in building envelopes: A review. Applied Energy, v. 165, p. 707-734, 2016. 